\title{
La importancia hermenéutica de la Introducción al "Tractatus» de Wittgenstein, de Elizabeth Anscombe
}

\author{
Horacio Luján Martínez \\ Universidad Nacional de Rosario. \\ Escuela de Idiomas y Escuela de Filosofía de la Facultad de Humanidades y Artes \\ horaciomartinez68@gmail.com
}

Fecha de recepción: 2-12-2019

Fecha de aceptación: 17-5-2021

\section{Resumen}

Nuestro artículo analiza el libro de Elizabeth Anscombe destacando su carácter político. Cuando decimos "político» nos referimos a que desde su publicación opera como un filtro de exclusión de otras lecturas del Tractatus. En especial entendemos este texto como una expulsión a priori de las lecturas que privilegian la influencia de Arthur Schopenhauer. Describiremos las estrategias implícitas y explícitas del texto para dificultar e imposibilitar la lectura del libro de Wittgenstein en clave ética, estética o mística. Señalaremos la distancia que, de modo crítico, el libro de Anscombe construye a manera de canon de lectura. Consideraremos, también, hasta dónde llega la influencia del filósofo de Frankfurt sobre el joven Wittgenstein y la actualidad de una lectura schopenhauereana de la primera obra del pensador vienés.

Palabras clave: filosofía analítica; políticas de interpretación filosófica; teoría de la lectura

Abstract. The hermeneutic significance of Elizabeth Anscombe's Introduction to Wittgenstein's Tractatus

Our article discusses Elizabeth Anscombe's book, highlighting its political character. When we say "political» we mean that since its publication it has operated as a filter for the exclusion of other readings of the Tractatus. In particular, we understand this text as an a priori exclusion of readings that prioritised Arthur Schopenhauer's influence. We will describe the implicit and explicit strategies the text uses to make it difficult or impossible to undertake an ethical, aesthetic or mystical reading of Wittgenstein's book. We will highlight the distance that Anscombe's book, critically, creates as literary canon. We will also consider how much influence Schopenhauer had on the young Wittgenstein, and the current state of a Schopenhauerean reading of Wittgenstein's first work.

Keywords: analytical philosophie; politics of philosophical interpretation; theory of reading 


\section{Sumario}

$\begin{aligned} \text { 1. Introducción } & \text { 5. ¿ंDecir, mostrar o adivinar } \\ \text { 2. Un libro que condiciona al lector } & \text { «chopenhauer»? } \\ \text { 3. Lo que "muestra» la Introducción } & \text { 6. Conclusión } \\ \text { de Anscombe: «Decir» Schopenhauer } & \text { Referencias bibliográficas } \\ \text { para nombrar un error } & \\ \text { 4. Wittgenstein y el Tractatus: } & \\ \text { Schopenhauer se «muestra» } & \\ \text { pero no se «dice» } & \end{aligned}$

\section{Introducción}

A sesenta años de la primera edición de Una introducción al "Tractatus» de Wittgenstein, de G.E.M. Anscombe, su relectura da lugar a un análisis del pasado reciente y de la «filosofía como institución». Adelantamos que iremos a considerar esta ya clásica presentación como el diseño de un laberinto en el que el lector no puede más que perderse.

Esta obra actuaría como "plataforma» a través de la cual el pensamiento de Schopenhauer ingresaría de modo clave en los estudios sobre el Tractatus. Dicho «ingreso" era inevitable una vez que se diesen a conocer cartas, versiones previas y cuadernos personales del pensador vienés. Así, las interpretaciones del Tractatus en términos de "mística», "ética» y "metafísica alemana» se tornarían frecuentes y desafiarían las lecturas que, privilegiando la lógica, pregonaban el fin de la metafísica. Pensamos que la escritora británica intuía y contaba con estas consecuencias, que no parecían ser convenientes. No postulamos ninguna teoría conspiratoria, pensamos antes en una preocupación coetánea a la publicación del libro. En los tiempos posteriores a la Segunda Guerra Mundial hubo una reacción que combinó pertinencia con equívoco hacia los filósofos asociados a «lo irracional» con que se identificaba al nacionalsocialismo. Así cayeron en desgracia las obras de Schopenhauer y Nietzsche, acusadas de ser parte de un supuesto «asalto a la razón».

Dado este contexto cultural, no es descabellado pensar que Anscombe se sintiese obligada a hacer algo al respecto. También debemos recordar que, en la época de su edición, era hegemónico un consenso de indiferencia hacia las proposiciones del Tractatus que se referían al misticismo, la ética y la voluntad.

Si el significado del Tractatus iba a incluir el nombre de Schopenhauer, su introducción debía contenerlo, mencionándolo pero nunca en clave exegética. A este nombre no lo dice, lo «mal-dice». ¿De qué modo? Con recursos ad hominem y de un supuesto encomio que naufraga en la indiferencia y la advertencia hacia ese nombre anatema que fue el del autor de El mundo como voluntad y representación.

Dentro de este marco, el de atenuar o anular influencias que retrotraían a tiempos oscuros, es en el que leemos el libro de Elizabeth Anscombe. 


\section{Un libro que condiciona al lector}

Se espera de un libro introductorio que facilite el entendimiento de un asunto, a través de la identificación y la descripción de sus tópicos, en un ejercicio de objetividad panorámica. En este caso, la autora se desentiende de esa expectativa declarando haber abordado los problemas que a ella le parecen más importantes (Anscombe, 1977: 11). Estos intereses remiten al lugar de la lógica de Frege y Russell y a la "teoría de las proposiciones como imagen", la cual se originaría en la influencia del pensamiento de Schopenhauer ${ }^{\text {. }}$.

La voz del texto oscila a modo de mantener una disimetría jerárquica entre autor y lector. Crea una distancia entre ellos a través de formas discursivas que exhiben irritación o subestimación. Así, por ejemplo, lo escrito hasta ahora sobre el Tractatus «[...] ha sido tontamente trivial» (Anscombe, 1977: 3), o, por otra parte: «Debemos recordar que Wittgenstein recibió una fuerte impresión en sus lecturas de Schopenhauer, cuando era joven [...]» (Anscombe, 1977: 194).

La mencionada "oscilación» se produce entre la «ignorancia absoluta» del lector y la «verdad como revelación» de la autora. Esta dramatización encuentra su auge cuando se trata de explicar "solipsismo», "voluntad» y todo lo relacionado con Schopenhauer.

No es nuestro objetivo determinar si se trata de una estrategia consciente o de una actitud espontánea condicionada por el aludido Zeitgeist de postguerra. Solo decimos que se repite a lo largo del texto y dicha reiteración exige perplejidad: el lector ignora Frege, Schopenhauer y cuestiones de lógica contemporánea. Este desconocimiento es completo. La autora solo parece llevar a cabo su narrativa si es bajo el signo de una urgencia, la del «lector tabula rasa». Su libro está dirigido a quien no solo no entendió el Tractatus, sino que no se atrevió a tirarlo a la basura (Anscombe, 1977: 8). Esta definición evidencia que el espacio que ocupa la ignorancia es absoluto y nada docto. Tamaño desconocimiento solo se elimina diciendo la verdad de modo también completo y absoluto, como veremos. El libro deja muy claro no solo que no sabemos, sino también que ignoramos lo que no sabemos. Este doble desconocimiento nunca será restaurado y aquello que no sabemos es de una importancia fundamental.

Así, la línea de argumentación comienza a exhibir trazos cada vez menos definidos. Después de prometer que por fin dirá toda la verdad, en su com-

1. La afirmación es controvertida: el concepto Bild, traducido como imagen o figura en español, aplicado a la proposición se fundamentó en una mentada anécdota según la cual Wittgenstein habría asistido a la simulación de un accidente automovilístico en París. Hay genealogías que vinculan el concepto a la influencia de Heinrich Hertz (Simóes, 2012). Vale destacar también que la representación (Vorstellung) schopenhaueriana es producida a través del «cuádruple principio de razón suficiente», el que prescinde de cualquier especie de isomorfismo, «el mundo es representación», por lo que no es necesaria la coincidencia de estructuras entre mundo y lenguaje, núcleo de la relación entre proposición y «estado de cosas» o "hechos», fundamental en el Tractatus. No es el caso de la "representación schopenhaueriana", donde dicho "principio» hace de la individuación un destino de raigambre platónica y no una situación relacional o «estado de cosas» (Sachverhalten). 
pleta extensión, la autora termina contando una anécdota personal de Wittgenstein o manifestando algo que no solo no encaja en lo anterior, sino que lo niega. Son «actos de habla» grandilocuentes de los que volvemos con las manos vacías.

Esta estrategia "geopolítica» que diseña a priori el lugar de los interlocutores es la que permite el surgimiento de una «narrativa colateral» en las entrelíneas de lo que se presenta como «literal $»^{2}$.

Lo que diremos a seguir es una de las afirmaciones que nuestro ensayo defiende y que debe ser complementada con otras definiciones. El objetivo de la autora no era tanto el de «introducir» a la lectura del Tractatus, sino el de fiscalizar lo que era introducido, aún como mera posibilidad, en dicha obra.

\section{Lo que «muestra» la Introducción de Anscombe: «Decir» Schopenhauer para nombrar un error}

En el inicio la autora declara que se extenderá sobre las obras de Schopenhauer y Frege, dada su importancia en la estructura del Tractatus. Promete presentarnos al "verdadero Schopenhauer» y así alcanzar el entendimiento de conceptos oscuros como solipsismo, entre otros. Sin embargo, los capítulos siguientes explican la grandeza de la lógica de Frege, el auténtico héroe olvidado por los lectores del Tractatus. Cuando llega el momento de hacer lo propio con el autor de El mundo como voluntad y representación, vemos una sucesión de críticas esterilizantes.

La Introducción exhibe su fisionomía de palimpsesto en la composición de sus personajes. El «verdadero Schopenhauer» que nos será presentado se opone al «mitológico». Pero el mito que describe Anscombe y que, supuestamente, rodea y cubre a la filosofía de Schopenhauer estimula algo de suspicacia. Dicho mito vincula su filosofía de la voluntad, junto con la de Nietzsche, al nazismo. Más allá del hecho de que los imaginarios tienen una lógica propia y peculiar, cuesta asociar una filosofía tachada de pesimista, identificada con el budismo y el cristianismo, cuya meta era la eliminación de la voluntad y pregonaba una ética de la compasión; con la voluntad viril atragantada de racismo pseudocientífico y esencialmente violenta del nazismo. No es imposible que algún desavisado relacione Schopenhauer con el nazismo, pero tendría que sostener una lectura de la irracionalidad y la voluntad que no pasase de lo nominal para pregonar identificaciones, ya que la comparación de significados nunca los aproximaría.

En el caso de Schopenhauer el mito que afecta al Tractatus es el de que su filosofía defiende alguna clase de solipsismo. Es exactamente este el núcleo problemático del texto. Lo que anuncia es desvelar el significado del solipsismo, y eso solo se obtiene a través del conocimiento de El mundo como voluntad

2. Tomamos la categoría de «narrativa colateral» del texto de Evgenia Cherkasova «A filosofia como narrativa colateral: O filosófico, o literário e o fantástico», en Carel, Havi y Gamez (2008: 187-194). 
y representación. Pero el solipsismo es verdadero de un modo inocuo, se identifica, esto es, se subordina al realismo. El solipsismo de «El mundo es mi mundo» es un momento, el de la intuición mística de ver ese mundo como un todo limitado. Limitado por la estructura lógica del único lenguaje que entiendo. Si el solipsismo no se entiende como la descripción de ese momento y se lo toma como una "teoría del sujeto" en el Tractatus, se lo condena al absurdo. De ese modo, se anula la posibilidad de cualquier lectura ética. Y eso es lo que acontece: se dice que Schopenhauer era solipsista, afirmación claramente errada, y después se enfatiza la influencia sobre el «joven» Wittgenstein.

En la definición que Roland Barthes da del mito encontramos la descripción de lo que sucede en el texto que analizamos: «El mito no niega las cosas; su función es, por el contrario, hablar de ellas; simplemente, purificarlas, inocentarlas, fundamentarlas en naturaleza y en eternidad, darles una claridad, no de explicación, sino de constatación [...]» (Barthes, 2006: 235).

Lo que caracteriza al libro como palimpsesto es la exposición velada de una lectura triunfante - la que privilegia la lógica - sobre lecturas éticas, místicas o que destacan el papel de la voluntad.

Cuando decimos que el libro no espera al lector, estamos señalando que su edición se produce dos años antes que la publicación de los Cuadernos de notas (1914-1916), material que sustentaría o haría objeto de debate su tesis principal.

Nuestra presentación crítica no puede dejar de mencionar el nombre de quien firma como autora, pero no busca tanto cuestionar la persona de Elizabeth Anscombe como mostrar lo que se podía leer cuando se leía el Tractatus.

Lo que queremos decir es que el Tractatus ve la luz en el período de entreguerras, de movimientos políticos mesiánicos que invocaban elementos místicos en un ejercicio burdo de sincretismo populista. En ese contexto, ¿qué tipo de lectura mística hubiera estimulado o se le hubiese adjudicado a la obra?

Creemos que a veces se enfatiza el papel del neopositivismo sobre la interpretación del Tractatus, sin tomar en cuenta el contexto político y social de la época. La operación hermenéutica de Elizabeth Anscombe no debe ser considerada fuera de las condiciones de posibilidad en que lo místico e irracional podrían conjugarse como violencia y terrorismo de estado.

Es indudable el valor histórico del libro, el corte que introduce en la cronología de las interpretaciones. Su divulgación pone en marcha el fin del «monopolio interpretativo» inaugurado por el positivismo lógico y ejercido hasta comienzos de la década de 1960. Pronto se comenzaría a sospechar que tal dominio se debió a falta de alternativas ${ }^{3}$. Cabe aclarar que lo que llamamos «monopolio» no exige coincidir en todos los pasos con la argumentación del

3. Es correcto vincular el "positivismo lógico» al Círculo de Viena, pero es necesario aclarar que este último tuvo corta duración, interrumpido por la Segunda Guerra Mundial y por la persecución nazi de sus miembros. Cuando aludimos al «monopolio de interpretación» no apuntamos al Círculo, sino a su lectura, que, junto con las que aproximaban el Tractatus a la filosofía kantiana (Eric Stenius entre otros), ocupó el centro de atención a lo largo de décadas. 
"positivismo lógico», sino considerar contradictorios a los aforismos que, «mostrando» el sentido, llevan al silencio.

Establecer vínculos entre el pensamiento de Schopenhauer y la filosofía del llamado "primer Wittgenstein", antes de 1959, no era algo improbable, sino imposible. Los fundamentos de esta imposibilidad son claros: el material publicado — tarea de la cual G.E.M. Anscombe se encargó- no incluía todavía textos clasificados como "personales». Así, los diarios escritos durante la Gran Guerra que serían la base del Tractatus y que abundaban en observaciones sobre Schopenhauer, ética, religión, etc., se tornaron de conocimiento público solo a partir de 1961. También la carta que Wittgenstein enviara al editor Ludwig von Ficker en la que declaraba que "el Tractatus es un libro de ética» se publicó en 1969, y hasta la propia Conferencia sobre ética dada en Cambridge en 1929 vería la luz en un número de Philosophical Review de 1965.

Decidirse por la publicación de estos papeles inéditos caracterizó, sin duda, un momento político en la historia reciente de la filosofía. Nuestra autora sabe de la importancia de la obra de Schopenhauer en el corpus del Tractatus. No obstante, así como asumió el compromiso ineludible de anunciar esta novedad, que alterará radicalmente las lecturas futuras, también tomó partido contra la inclusión de los conceptos de Schopenhauer como elementos hermenéuticos legítimos. De este modo, solo le concede el papel de influencia en lo que respecta al "mundo como representación", que reaparece en el Tractatus como «mundo de los hechos, no de las cosas». Para la autora, el concepto de «voluntad» de El mundo como voluntad y representación nunca fue adoptado por el autor del Tractatus.

La propuesta de interpretar aspectos del libro a partir de la influencia de Schopenhauer es precedida por una curiosa aclaración. Se nos dice que Wittgenstein había leído El mundo como voluntad y representación a los 18 años. Es la única ocasión en que se nos informa acerca de la edad en que el filósofo realiza una lectura. Esto mal esconde la subestimación del Wittgenstein lector (as a boy).

Si vemos la secuencia de aserciones, observamos que toda la lectura del lugar de Schopenhauer en el pensamiento del joven Wittgenstein depende fundamentalmente de que se considere manipulable y sin carácter propio en su período adolescente a la misma persona a quien se llamó "genio" y que desbordaría carácter pocos años después.

Advertimos que nos interesa describir «los movimientos del pensar» del texto, antes que demandar responsabilidades. Estos movimientos que llevan a la publicación de un texto poco objetivo no son solo individuales. Se debe prestar atención al contexto en que se lo recibe. Esto tiene que ver con el lugar que la historia de la filosofía le dio a Schopenhauer, tratado siempre como una visita no deseada. En nuestra cultura existen premisas que forman convicciones tácitas sobre lo individual y lo social, que rechazan cualquier consideración de lo irracional que no sea totalmente negativa. Ya volveremos sobre esto.

Sus críticas al filósofo alemán mezclan preconceptos, lugares comunes, una buena dosis de terquedad y giros retóricos variados. Ante esta situación no 
podemos menos que considerar la obra, un texto político, con otra intención que la declarada. Como diría Wittgenstein reflexionando sobre religión: «Para ser un error, es un error demasiado grande» (Wittgenstein, 1992b: 139).

Como adelantamos, Anscombe asegura que conceptos obscuros como solipsismo o límite ganan sentido a partir de la lectura de Schopenhauer. El tono empleado es el de quien trae buenas noticias. Dado su lugar privilegiado como heredera intelectual, las expectativas deben haber sido enormes. Pero este entusiasmo deviene una cuestión espinosa cuando, en el capítulo final, titulado "Misticismo y solipsismo», la escritora irlandesa denuncia la incoherencia de los términos de la filosofía de Schopenhauer que se encuentran en el Tractatus. El pensador alemán influenció a Wittgenstein, pero solo se lo responsabiliza en todo lo que este pensó erradamente.

Hay que destacar dos cosas: el filósofo alemán habría influenciado en la teoría del lenguaje de Wittgenstein, afirmación delicada si no se la desarrolla, ya que es la lógica de comienzos del siglo xx la que constituye dicha teoría. La segunda observación complementa a la anterior: Anscombe utiliza el término idea. Muchas traducciones al inglés del más conocido libro de Schopenhauer lo titulan The world as Will and Idea. Traducción errada, «idea» (Idee) y «representación» (Vorstellung) están muy lejos de ser sinónimos ${ }^{4}$. Como veremos, esto refuerza el equívoco de que su autor tiene una posición solipsista respecto al mundo.

El tema del solipsismo en el texto de Wittgenstein comienza con esta afirmación: «Los límites de mi lenguaje significan los límites de mi mundo» (TLP 5.6). Si el mundo está formado por la totalidad de los hechos y si el lenguaje tiene la sola función de retratarlos, está claro que los límites del mundo y del lenguaje coinciden. El problema comienza a vislumbrarse con la utilización del posesivo mi relacionado con mundo.

El objetivo principal de la ópera prima del pensador vienés es establecer la diferencia entre lo que se puede «decir» (sagen) y lo que se puede "mostrar» (zeigen). Pero, y esa es buena parte de la controversia respecto al libro, Wittgenstein parece indicar por última vez aquello que debe ser callado:

Esta consideración ofrece la clave para saber en qué medida el solipsismo es verdadero. Lo que el solipsismo significa es absolutamente correcto; solo que es algo que no se puede decir, sino que se muestra.

Que el mundo sea mi mundo es lo que se muestra en esto: los límites del lenguaje (el único lenguaje que yo entiendo) significan los límites de mi mundo. (TLP 5.62)

4. «La noción schopenhaueriana de “representación” está más cerca de la relación simbólica o lingüística entre pensamiento y realidad que la epistemológica — y, de acuerdo con Wittgenstein, psicologista - concepción de "idea" como representación mental de una cosa. En este sentido "Vorstellung" de Schopenhauer pudo haber contribuido a la creación de la noción wittgensteiniana de "Abbildung" (representación) (cf. TLP 2.151, 2.22. 4.015)» (Marrades Millet, 2011: 67). 
El solipsismo es verdadero, pero esto no es más que una figura para indicar que no se puede pensar lo impensable, ni, por eso mismo, decir lo impensable, lo que lleva a la conclusión de que no existe otro mundo que aquel que estoy pensando.

Estas proposiciones sobre el solipsismo provocaron desconcierto, y un famoso error de traducción —al pasar del original alemán al inglés— tornó este tema centro de debate por décadas. Precisamos detenernos un poco en este error, porque también dice al respecto de la interpretación de Anscombe.

En lo siguiente acompañamos el desarrollo llevado a cabo por Jaakko Hintikka en su artículo "On Wittgenstein's Solipsism»" . El error en cuestión se refiere al paréntesis que se encuentra casi al final del parágrafo: «Daß die Welt meine Welt ist, das zeigt sich darin, daß die Grenzen der Sprache (der Sprache, die allein ich verstehe) die Grenzen meiner Welt bedeuten» (cursivas nuestras).

El problema de la traducción nace en la edición inglesa de Ogden y Ramsey de 1922, que interpretó allein como refiriéndose a ich y no a Sprache y tradujo el texto alemán como «the language which only I understand» («el lenguaje que solo yo entiendo»). Lo que acabó confirmando este error de traducción fue el hallazgo en 1964 de un ejemplar de la primera edición corregido a mano por el propio Wittgenstein.

Un tercer documento que refuerza la idea de que en 5.62 la palabra allein se refiere a Sprache y no a ich (sujeto de verstehe) es el Prototractatus, redacción de una versión preliminar del Tractatus. Encontramos allí (en la página 60 del facsímil de estos manuscritos) el siguiente texto con las marcas del autor: «5.3353 Daß die Welt meine Welt ist, das zeigt sich darin daß die Grenzen der Sprache (der Sprache die allein ich verstehe) die Grenzen meiner Welt bedeuten». En este rasguño donde el fragmento del parágrafo 5.62 que nos ocupa aparece bajo el número 5.3353, Wittgenstein subraya los posesivos que se refieren al mundo (Welt) y, más importante aún, subraya el artículo der y el adjetivo allein, vinculando así claramente uno a otro.

Esta traducción «viciada» fue adoptada por Anscombe en la primera edición de 1959 de su Introducción. En la segunda edición de 1965 acusó recibo del error de traducción y señaló el hecho en una nota a pie de página. Curiosamente, esto no alteró su convicción sobre el solipsismo del Tractatus.

La autora británica manifiesta que el pasaje sobre el solipsismo también derivaría de la lectura de Schopenhauer, ya que este afirma que «El mundo es mi idea». El "yo» de este solipsismo no es un cuerpo, un alma o una substancia, sino que «se refiere al centro de la vida, o el punto a partir del cual se ve todo" (Anscombe, 1977: 195). Es la idea de un mundo limitado, el sentimiento del mismo, la que introduce lo místico en la consideración del solipsismo wittgensteiniano. Según la comentadora, habría tomado el término

5. Quien llamó por primera vez nuestra atención sobre el artículo de Hintikka fue Pilar López de Santa María Delgado en su Introducción a Wittgenstein: Sujeto, mente y conducta (López, 1986: 59). Desarrollamos con mayor extensión y detalle este problema de traducción en Martínez (2001). 
misticismo de Russell, opinión que no compartimos, según ya expusimos en otra ocasión ${ }^{6}$. Brian McGuinnes es tajante al respecto:

No es verdad que Wittgenstein hubiera leído el ensayo de Russell «Misticismo y Lógica», cuando compuso el Tractatus. Este ensayo fue publicado en julio de 1914 y la última visita de Wittgenstein a Inglaterra antes de la guerra fue en octubre de 1913. Si lo leyó en 1914, parece que se lo sacó de la cabeza por un buen tiempo, ya que los «temas místicos» no aparecen en sus Cuadernos de notas hasta el 6 de mayo de 1916, cuando las proposiciones 6.371 y 6.372 del Tractatus son esbozadas por primera vez. (McGuinness, 1966: 305)

Es el problema del sentido de la vida del que se ocupa el misticismo. Este problema no puede ser resuelto a través de las ciencias y su modo de interrogar. El sentido del mundo debe quedar fuera del mundo, esto significa que es inefable. En función de este sentido del mundo Elizabeth Anscombe va a considerar la voluntad del Tractatus. La tarea o el problema a que Wittgenstein se refiere cuando dice que "Los hechos pertenecen todos a la tarea propuesta (Aufgabe) y no a la solución» (TLP 6.4321) es la propia vida. Esta tarea que se nos propone está acompañada de leyes de la forma «debes» o «no debes», a lo que Wittgenstein responde: "¿ৃ qué si no lo hago?».

Wittgenstein piensa que una acción ética debe tener alguna especie de premio o castigo, pero que estos deben residir en la acción misma (TLP 6.422). Una atónita Anscombe se pregunta: «¿Qué es la acción misma?».

La autora señala que la palabra alemana Aufgabe denomina las tareas que se le dan al alumno en la escuela. Insiste en traducir el término como "tarea propuesta», lo que tiene sentido en el contexto escolar, donde maestros o profesores atribuyen esas actividades. Llevada esta acepción al problema del sentido de la vida, parece no cerrar satisfactoriamente: una tarea propuesta suena a "heteronomía» en sentido kantiano. La respuesta puede ser pensada en torno de «la acción misma», con auxilio de anotaciones de los Cuadernos de notas que fueron omitidas de la versión final del Tractatus.

Como en otros lugares del libro, cierra y refuerza su argumento con una anécdota personal referida a Wittgenstein: «La vida es como un niño que hace cuentas. (Hacia el final de su vida seguía usando la misma analogía)» (Anscombe, 1977: 198).

Si pensamos esta «tarea» en los términos de una voluntad que se identifica con su obrar, y no como causa de un efecto, entenderemos el «solipsismo» no solo en vinculación con el "misticismo», sino como una «ética de la inmanencia», según la cual «querer» $\mathrm{y}$ «hacer» son sinónimos.

Curiosamente, Anscombe repara en esos fragmentos donde se realiza esta identificación, pero, ocupada en leer las proposiciones de Wittgenstein sobre la voluntad como crítica y corrección de las posiciones de Schopenhauer, no las considera tesis positivas.

6. Difícilmente Russell, ateo y liberal, influyera en Wittgenstein en materia religiosa. Abordamos el tema en Martínez (1998). 
El juicio negativo de los conceptos y la filosofía schopenhaueriana la lleva a afirmar que quizás la vinculación entre voluntad, solipsismo y límites sea "[...] la parte del Tractatus que pareciera estar más evidentemente equivocada» (Anscombe, 1977: 199). «Misticismo» y «solipsismo» ven erosionada su transcendencia cuando la comentadora declara no comprender el papel de una "[...] quimérica voluntad que no hace nada en el mundo, pero solamente altera los "límites" del mundo" (Anscombe, 1977: 199).

En lo que sigue resumiremos algunas "complicaciones» en la lectura de Anscombe:

a) Tomar al solipsista y al solipsismo como literalmente reales o existentes. Así como el «relativista», el «solipsista» es un "personaje conceptual», una ficción, un "as if». Si alguien en la historia de la filosofía hubiese postulado esas convicciones como saberes, a la hora de ejemplificar se darían los nombres de los filósofos criticados. Como el «contrato social», el «estado de naturaleza» o el "genio maligno», el solipsista funciona como un caso extremo y ficticio que da auxilio a una argumentación. Del hipotético relativista que contradice su posición, Karl-Otto Apel retira el concepto de "autocontradicción performativa» para dar un ejemplo. En Wittgenstein la palabra solipsismo denomina el momento de proyección de la proposición sobre el mundo. Es un «yo» el que realiza esta proyección, pero lo hace en el único lenguaje que existe y que comparte estructura lógica con el mundo. El «solipsismo» solo es la caracterización "monológica» del lenguaje que se opondrá al lenguaje dialógico de las Investigaciones filosóficas.

b) No solo por este carácter ficcional Schopenhauer no era solipsista, sino también porque el sujeto no puede producir el objeto, ni viceversa. Sujeto y objeto son inseparables, y se funden en la representación. No hay causalidad entre ellos. Tanto realismo como idealismo extremo están errados. Schopenhauer tachaba de solipsista a Fichte, de hecho. El rechazo del idealismo extremo es claro: «La cuestión acerca de la realidad del mundo exterior, tal como la consideramos hasta ahora, siempre se originó en un engaño de la razón consigo misma» (Schopenhauer, 2005: I, 5). Entre sujeto y objeto no hay relación de causalidad, ambos obedecen al principio de razón suficiente.

c) $\mathrm{Al}$ anunciar por primera vez su novedad exegética, Anscombe dice que la doctrina de Schopenhauer es la del «mundo como idea». Así, torna sinónimos idea y representación, dos conceptos claramente diferenciados en la obra de Schopenhauer, que siempre afirmó que su filosofía heredaba y reelaboraba tres corrientes de pensamiento o contemplación: budismo, platonismo y kantismo.

De esta manera, el concepto de idea es platónico. Significa las formas eternas a través de las cuales la "Voluntad» se objetiva en el mundo, es decir, se torna fenómeno. El concepto de representación es kantiano. Tanto en Kant como en Schopenhauer, representación es construcción u organización 
de la experiencia, solo que, en lugar de la deducción transcendental de las categorías, la "representación» schopenhaueriana es construida a través del cuádruple principio de razón suficiente.

Cabe recordar que en el mundo anglosajón el título de la conocida obra de Schopenhauer es The world as will and Idea. Y Anscombe es consciente de ello. Es en el último capítulo, donde la estrategia es reforzar un Schopenhauer solipsista, en que ella usará solamente el término idea.

$\mathrm{Al}$ identificar representación con idea sin especificar la acepción platónica de esta última, se da a entender que el mundo es producto de alguna acción mental. Así se lleva a cabo la invención de un Schopenhauer ingenuo y mal filósofo, que será presa fácil de la crítica empirista británica y de los que solo encuentran lógica en el Tractatus. Su metafísica se ve reducida a exacerbación psicológica, con lo que a Schopenhauer se le atribuirá por siempre una postulación y una defensa del solipsismo.

d) Anscombe no distingue entre voluntad empirica y voluntad metafisica, y queda convencida de la impotencia de la voluntad sobre el mundo. Esta definición se aplica a la voluntad metafísica, que no puede cambiar ni producir hechos en el mundo, sino que puede alterar los límites del mundo, lo que significa mudar el modo de ver el mundo de los hechos.

e) Debido a lo anterior, no entiende una ética en la cual "premio y castigo» residan en la acción misma. Es una ética de la inmanencia donde el mundo del feliz será el que contemple todos los hechos, y el del infeliz intente mudarlos. Cualquier alteración de los hechos que me beneficie será una «gracia del destino». Esta es «la parte más evidentemente equivocada del Tractatus» para Anscombe (1977: 199).

El Tractatus no afirma categóricamente que "el solipsismo es verdadero», sino que delimita "en qué medida» lo es. La definición es restrictiva, lo que comprobamos al continuar la lectura del parágrafo: «Lo que el solipsismo quiere significar es enteramente correcto, solo que no se puede decir, sino que se muestra» (TLP 5.62). Obsérvese el uso de esos dos verbos (itálicas del autor): «quiere significar». Denotan una operación o un proceso no finalizado o alcanzado. El solipsismo es "verdadero" en la medida en que coincide con el realismo. Es el «realismo» el objeto de esa proposición. El solipsismo se disuelve en este. Enunciarlo como verdadero no aporta ningún conocimiento, ya que, antes que afirmar la creación mental del mundo, lo que hace es decir que los hechos no están predeterminados y, por eso, «el mundo es mi mundo", o sea "representación» a partir del isomorfismo que comparten lenguaje y mundo.

Esta «representación» o «figuración» es cualquier cosa menos psicológica o subjetiva, ya que se realiza con el único lenguaje que entendemos. Como vimos, la definición "el solipsismo es verdadero» fue entendida de modo literal por un error de traducción al pasar el texto del original alemán al inglés.

El controvertido término solipsismo se refiere a que si bien las estructuras del mundo y el lenguaje que las describen son a priori, no lo son ni su apli- 
cación ni los hechos que significamos. El sujeto solipsista es el sujeto metafísico que debe «intuir», esto es, «ver» sin intención ni mediación, ese mundo y sus límites.

El sujeto es solipsista porqué «el mundo es mi mundo», lo que significa que yo protagonizo lo que veo, pero como lo veo a través del único lenguaje que entiendo, cualquier otro puede ver lo mismo. Solipsismo coincide con realismo, porque si bien la experiencia puede ser singular, el lenguaje con que se la describe es universal, no un «lenguaje privado», como lo denominará posteriormente en las Investigaciones filosóficas.

La Introducción de Anscombe es la primera interpretación que asume la importancia del «misticismo» vinculándolo con el «solipsismo». El «misticismo» denota la acción de ver "el mundo como un todo limitado». Como esos límites no fueron impuestos o creados por mi voluntad $\mathrm{u}$ otra voluntad humana, se impone el silencio — que no es subordinación ni devoción — ante esa voluntad ajena que podemos llamar «Dios».

A la voluntad desiderativa, fuerza ciega, Wittgenstein le opondrá un modo de ver, el del mundo como un todo limitado. Para que esa acción sea llevada a cabo es necesaria una intuición (Anschauung). Ver «el todo y sus límites» es un «ver sin mediación», sin imperativos ni raciocinios. Es lo místico, un ver inmediato o intuitivo. Denominar este ver de "místico» no tiene nada de esotérico ni, mucho menos, devocional. Es un ver que transforma al «observador», como las epifanías o las revelaciones en las personas santas o que se convierten a una religión. Estamos ante una analogía. Ver el mundo como un todo limitado es aprender la correcta visión del mundo, aquella que puede ser colocada en proposiciones que muestran la forma lógica que el mundo y el lenguaje comparten.

La idea de un sujeto representante que se encuentra en el mundo también exige consideración diferenciada. Así como en el campo de visión no vemos el ojo, el sujeto metafísico no puede ser visto en el mundo (TLP 5.633).

Wittgenstein comprende el pensamiento de Schopenhauer y reelabora las disposiciones y facultades de la "Voluntad de vivir», esencia del mundo, tornándola «voluntad metafísica humana».

Demostraremos que lo escrito en los Cuadernos de notas (1914-1916) sobre la voluntad schopenhaueriana es omitido del Tractatus porque uno de los verbos psicológicos por excelencia, desear, parte fundamental de esta reflexión, solo puede ser pensado como expresión de una "cosa en sí»; vieja piedra en el zapato del llamado «idealismo alemán», algo que excedía y hasta contradecía los objetivos del joven Wittgenstein.

\section{Wittgenstein y el Tractatus: Schopenhauer se «muestra» pero no se "dice»}

Según nuestra comentadora, Wittgenstein compartía la concepción de «mundo como idea o representación», pero no concordaba con la de «mundo como voluntad». Esta observación es bastante insatisfactoria, porque sin «voluntad» no hay «representación», por lo que no se puede simplemente elegir uno de 
los conceptos sin alterar el todo. Si Wittgenstein rechaza o da un nuevo significado a los términos y a las cuestiones de este pensador, aclarar esas divergencias es más que necesario. Entre otros motivos, porque buena parte del glosario y de las cuestiones que presenta el Tractatus reflejan, en buena parte, la obra más conocida de Schopenhauer.

En oposición a esta afirmación demostraremos que Wittgenstein no rechaza el concepto de voluntad, sino que lo reformula al transformarlo en «un modo de ver al mundo" por parte del sujeto.

Wittgenstein, al darle forma final al Tractatus, mantiene las preocupaciones y el vocabulario que se encuentran en El mundo como voluntad y representación. ¿Qué lo lleva a omitir deliberadamente el nombre de Schopenhauer? Un comienzo de respuesta puede encontrarse en la anotación de agosto de 1916:

Bien y mal solo entran en escena a través del sujeto. $Y$ el sujeto no pertenece al mundo, sino que es un límite del mundo. Se podría decir (schopenhauerianamente): el mundo de la representación no es ni bueno ni malo, sino que lo es el sujeto que quiere.

Soy consciente de la completa falta de claridad de todas estas proposiciones.

(Cuadernos de notas, 2/8/1916)

El filósofo vienés no parece dudar sobre la importancia de la filosofía de Schopenhauer, aunque declara su falta de claridad al respecto. Este parágrafo no aparece «literalmente» en el Tractatus, pero sí su contenido. Es el sujeto metafísico cuya voluntad no altera el mundo de los hechos, sino los límites del mundo. $\mathrm{La}$ «voluntad» que muda los límites del mundo no pertenece a ese mundo, sino que es su límite. Es esta "Voluntad» metafísica la que no se relaciona causalmente con el mundo de los acontecimientos: «El mundo es independiente de mi voluntad» (TLP 6.373). Aún si todo ocurriese como lo deseáramos sería solo una cuestión de suerte o una gracia del destino, ya que no hay conexión lógica entre la voluntad y el mundo (TLP 6.374).

La explicación de esto se encuentra en los Cuadernos de notas. La conexión de la voluntad (el querer) se establece con la «acción misma»:

Está claro: es imposible querer sin llevar a cabo ya el acto voluntario. El acto voluntario no es la causa de la acción, sino la acción misma. No se puede querer sin hacer. Si la voluntad ha de tener un objeto en el mundo, entonces puede serlo la acción intencionada. Y la voluntad ha de tener un objeto. (CN $4 / 11 / 1916)$

La «Voluntad» ética o metafísica quiere y hace sin mediación de una representación. Es la «Voluntad» que trasciende los hechos porque se relaciona con el "todo». Es la "voluntad ética» una voluntad inmanente, que no piensa sino que hace. Por eso la ética no podrá tener contenido, porque hacer es ver los límites del mundo con sentido. Esta identificación entre querer y hacer también la encontramos en El mundo como voluntad y representación. En este el cuerpo 
no es otra cosa que la voluntad objetivada - la voluntad convertida en representación-y no puede querer el acto sin percibirse a la vez como movimiento de su cuerpo. El acto de voluntad y la acción del cuerpo no son dos estados diferentes; no están en relación de causa y efecto, sino que son una y la misma cosa (Schopenhauer, 2005: II, 18).

Y aquí se separan las aguas entre lo que Wittgenstein tiene en común —el origen no racional de la razón, en particular-con el filósofo alemán y lo que comienza a pensar más allá de él y contra él.

Para realizar esto, Wittgenstein distingue entre querer (wollen) y desear (wünschen), términos que son indistintos en la obra schopenhaueriana: «[...] Desear no es hacer. Sin embargo, querer es hacer. [...] El hecho de que yo quiera un proceso consiste en que yo lo lleve a cabo, no en que haga otra cosa que cause el proceso [...]» (CN 4/11/1916). El «querer» se identifica con la acción, es la acción misma. Es la voluntad desiderativa la que se niega en TLP 6.373, y es solo la voluntad inmanente a la acción la que es reivindicada. La diferenciación entre el "desear» y el «querer», y la posterior identificación de este último con el "hacer» es el «movimiento» de Wittgenstein, para escapar de una voluntad como fuerza ciega y destino, que es la propuesta de Schopenhauer. Donde «desear» no es «hacer», "querer» sí lo es (Martínez en Balla y Tomasini Bassols [orgs.], 2014: 89-116).

Lo que se inicia a partir de la necesidad de distanciarse de Schopenhauer, de su "Voluntad» como "cosa en sí», es una reflexión activa que está siempre presente en anotaciones del filósofo vienés, no importa el año que se quiera analizar. La preocupación con los verbos psicológicos tiene una doble fuente de origen. El esfuerzo por separar o distanciar cualquier formulación lógica, o uso de la misma, de toda explicación causal que afirme o sugiera ser de origen psicológica.

La otra fuente de origen que reconocemos son los verbos que muestran el carácter activo y depredador de la "Voluntad» como esencia. Esta "quiere», «hace» o «desea». Todo a la vez y sin distinción. La salida nietzscheana fue pensar estos verbos como expresión del poder de la voluntad, un "poder-hacer» espontáneo. Lo que esa voluntad no consiguiese debía recibir otro trato, el del «amor fati» 7 .

Wittgenstein comparte algunos rasgos de la voluntad schopenhaueriana, aunque nunca su fatalidad. Nótese que de la inmanencia «querer-hacer» Schopenhauer concluye la inexistencia de «libre albedrío», algo impensable y sin lugar en la obra del vienés.

La diferencia es fundamental, «voluntad empírica» y «voluntad metafísica» son los nombres de una distinción ontológica en El mundo como voluntad y representación, la primera es voluntad humana, la otra es ser, «cosa en sí».

Encontramos ambas voluntades en Wittgenstein, pero estas denominan una distinción lógica, la que opera en la distinción entre decir y mostrar. Querer dentro del mundo de las posibilidades lógicas, lo que no significa resigna-

7. Ver, entre otros, el parágrafo 341 de La Gaya Scienza, de Nietzsche. 
ción o tomar un atajo que reúna el querer con lo querido. Querer algo en el mundo lógicamente posible no significa su obtención, significa querer con sentido y querer el sentido. Es de la lógica como transcendental que voy hacia el querer los hechos, independientemente de que su realización sea producto de una voluntad ajena.

Wittgenstein establece diferencias en el interior de la voluntad. Su objetivo es superar la distinción schopenhaueriana entre una «voluntad como cosa en sí» y una "voluntad humana». El pensador austríaco no quiere una "Voluntad» como fuerza ciega y fatalista. Mucho menos como «cosa en sí».

Schopenhauer sostenía un argumento lógico y otro ontológico con el que justificaba la «Voluntad» como principio metafísico. Con el primero sostenía que, si bien puedo querer un objeto o realizar una acción, no puedo "querer el querer». El «querer» no nace de una decisión, sino que es infundado. En última instancia no puedo justificar por qué quiero, lo que podemos justificar es el objeto querido, no la acción de querer. Eso torna a la «Voluntad» esencia del mundo, no solo humano, sino de la Naturaleza que sería expresión de esa esencia que solo sabe querer.

El argumento ontológico produce una convicción menor, se fundamenta en la imposibilidad de separar «esencia» de "existencia». Si la «Voluntad» es esencia, ella existe, porque es inconcebible una esencia inexistente.

La respuesta de Wittgenstein al argumento lógico es clara: «[... ¿ ¿No lo puedo producir? ¿Cómo qué? ¿Qué es lo que puedo producir? ¿Con qué comparo el querer cuando digo esto?» (Investigaciones filosóficas, \$ 611).

Las «voluntades» que Wittgenstein postula son humanas. La que llama «de metafísica» lo es porque su papel es "ver el mundo como un todo limitado". Este «ver» es místico y ético. Místico porque se llama a silencio ante lo que existe y que sentimos como hecho por una voluntad ajena. Ético porque esa voluntad debe asimilarse a los límites del mundo-lenguaje ${ }^{8}$.

La voluntad es impotente, esto no significa que no podamos realizar cosas que nos proponemos, sino que no podemos querer más que lo realizable. El querer es isomorfo a la acción, a lo que puede ser realizado en un mundo de hechos figurables. El desear encarna la "tendencia natural del espíritu humano» de transgredir las barreras del lenguaje y la figuración, los límites del único mundo-lenguaje posible?

Vencer esta tendencia significa una aceptación de los límites de la lógica, de lo pensable-decible. Precisamente este trabajo es el que le está asignado al sujeto de la voluntad ética, el sujeto metafísico o solipsista.

8. Ver Martínez (2010: 111-130).

9. La expresión "tendencia natural del espíritu humano» aparece al final de la Conferencia sobre ética. Tomamos la Conferencia como continuidad de la distinción entre lo que puede ser dicho y lo que debe ser silenciado, por lo tanto, más próximo a la esfera conceptual del Tractatus. Anscombe, en su artículo "La simplicidad en el Tractatus», afirma dicha continuidad y califica a la Conferencia como «extremamente tractatusiana» (Anscombe, 1989: 6). 
El mundo está estructurado lógicamente, y el lenguaje lo refleja porque comparte dicha estructura. Sin embargo, transgredimos este isomorfismo al usar el lenguaje para expresar cosas que no están en el mundo.

Aquí hay muchos aspectos para pensar. Si bien el Tractatus identifica el síntoma (el sentido de la vida como problema) y su «solución por disolución»: sentir lo místico, el mundo como un todo limitado; no dice ni muestra la causa. Si, como se anuncia en el prefacio, todos los problemas filosóficos derivan de un «mal entendimiento» del lenguaje, extrañamente tendríamos una causa cognitiva. Esto no condice con nada de lo que afirma Wittgenstein en el resto del libro, o donde se lo quiera leer.

En realidad no conseguiría explicar por qué transgrede las barreras del lenguaje y la de los hechos del mundo hasta la Conferencia sobre ética de 1929.

Con la omisión de los fragmentos de los Cuadernos en que se identifica «querer y hacer», lo que parece ser claro es que el verbo «desear» no puede tener otro significado que el de la acción concomitante al transgredir. De este modo, sería una disposición humana que se parece mucho a un pecado original, en el sentido de una voluntad que actúa contra sí misma. La otra opción es, precisamente, la que quiere evitar: pensar en una voluntad como esencia, que me arrastra al deseo sin fin ni finalidad.

Todo este escenario es algo que las interpretaciones lógicas del Tractatus nunca asumen ni explican: ¿Cómo se llega al silencio? Porque este no es inherente a la proyección o a la figuración o al nombrar. No hay ningún vínculo lógico entre el mal entendimiento del lenguaje y su transgresión. Y si al entender mal, transgredo, la causa u origen de la infelicidad es cognitiva, por lo que una ética es absolutamente posible.

La lógica limita al mundo, pero no hay nada en ella que me ayude a no transgredir esos límites. Es este el punto donde la palanca de la voluntad schopenhaueriana suele apoyarse. Lo que se encuentra en Wittgenstein es tan breve que solo puede ser alusivo. Son diversos los autores que el pensador vienés conjuga, pero cuando discurre sobre la voluntad, en especial en su obra de juventud, la fuente es única: Schopenhauer. Sea mencionado u omitido su nombre, Wittgenstein opera una crítica que lo lleva lejos de cualquier metafísica no racional. El problema es que al redactar el Tractatus no tiene una causa inmanente para substituir una causa metafísica.

La identificación o inmanencia entre «querer» $\mathrm{y}$ «hacer» da la base conceptual para entender por qué el solipsismo coincide con el realismo. Si «querer» $\mathrm{y}$ «hacer» son coetáneos e idénticos en sus condiciones de emergencia, esto es, uno no puede pensarse sin el otro, la clásica distinción entre "mente humana» $\mathrm{y}$ «mundo exterior» acaba disuelta en un punto sin extensión, lo que significa que la desaparición de su diferencia no deja rastros. El silencio debe ser conquistado, precisamente a través de la intuición del mundo como un todo limitado lógicamente. Lo que torna necesaria la búsqueda de «silencio» es el problema del sentido de la vida.

La cuestión es que todo esto que acabamos de decir apenas está mencionado y desarrollado en los Cuadernos. Entre otros inconvenientes, vemos que a 
la identificación o inmanencia entre «querer» $\mathrm{y}$ «hacer», Wittgenstein le agrega la existencia de un «desear». Esto recupera y mantiene una concepción de «Voluntad» como «telos» en sí misma, la fuerza ciega que actúa como principio metafísico. El «desear» lo obligaría a introducir una «Voluntad» que no podría llamar de «Dios», porque desea otro mundo que el de los hechos. También le exigiría explicar qué es lo que se puede querer y por qué no se debe desear. Lo que significaría, en suma, elaborar una ética que estableciese valores.

Wittgenstein no puede decir el nombre de Schopenhauer en el Tractatus Lógico-philosophicus, pero su texto lo "muestra» al identificar la ética con un trabajo sobre la «Voluntad». Esta es la «tarea» (Aufgabe) propuesta. Semejante a la transformación y a la superación del principio de individuación de «El Mundo" (Libro IV, $\$$ 69) ${ }^{10}$.

Con posteridad, en la década de 1930, conseguiría pensar esa inmanencia y afirmar la voluntad como fenómeno. "Cuando dije: "eso significaría no considerar la intención como un fenómeno", la intención recordaría aquí la concepción schopenhaueriana de la voluntad. Todo fenómeno nos parece inerte en contraste con el pensamiento vivo" (Gramática Filosófica VII, 97).

Anscombe utiliza un Schopenhauer todavía no superado por la reflexión posterior wittgensteiniana. Esto transforma todas las observaciones posteriores de Wittgenstein sobre la voluntad en una eterna corrección del Tractatus, y no lo que realmente es: la continuidad de una reflexión que lo lleva a nuevas perspectivas.

En realidad, la autora ofrece indicaciones de otros textos del filósofo vienés donde pueden encontrarse respuestas o paliativos que ella misma cita. Es probable que su lectura partiera de la convicción del Tractatus como libro, esto es, como obra cerrada en sí misma y no como texto que dialoga u omite - lo que también es una forma de relación-, observaciones hechas en otras ocasiones.

Cuando Wittgenstein retoma oficialmente la actividad filosófica, a partir de 1929, la «voluntad» será pensada al lado de otros substantivos y verbos que denoten una «interioridad» tan oculta como privilegiada. Por otro lado, «voluntad» es lo que hay que vencer para no quedar preso a usos unilaterales del lenguaje. Hasta el final de su vida insistirá en que los errores filosóficos derivan de la voluntad, no del entendimiento (Wittgenstein, 1997: 171).

Pero todo esto no estaba nada claro a comienzos de la década de 1920.

\section{5. ¿Decir, mostrar o adivinar «Schopenhauer»?}

La pregunta que surge es: si Schopenhauer fue tan importante para el contenido y la redacción del Tractatus, ¿por qué no hay ni una sola mención a él o a su obra en alguno de sus parágrafos?

Una respuesta conjetural y que acompaña a la de relación con un Zeitgeist que afirmamos al comienzo es la de que parece existir un «estigma Schopenhauer», según el cual sus lectores más brillantes pasan de la inspiración a la

10. Ver el desarrollo de esta analogía en Martínez (2001). 
aporía de modo imprevisible. Lo que comienza seduciendo acaba exigiendo nuevos conceptos, nuevas teorías y saberes.

Friedrich Nietzsche lo hará objeto de sus críticas más ácidas, al mismo tiempo en que piensa su «Voluntad de poder». Sigmund Freud oscilará entre el reconocimiento de una deuda intelectual y la negación ${ }^{11}$. Ludwig Wittgenstein acabará omitiéndolo. Los tres crearon algunos de sus conceptos más importantes a partir de la reformulación de su pensamiento. Pero el nombre Schopenhauer produce reacciones y urgencias que lo dejan más próximo a un «aviso de incendio». Y parece más que arduo hacer algo al respecto. Ya podemos reformular la afirmación de que "sin conocer a Schopenhauer no se entiende el Tractatus», para una definición alternativa más realista: «sin conocer a Schopenhauer no se entiende lo que el Tractatus deja sin resolver».

Los partidarios de lecturas logicistas deben entender que no considerar Schopenhauer y las nociones de "voluntad» que pueden encontrarse en el Tractatus es una posición que ya no se sostiene por sí misma. En realidad, coloca en incómoda evidencia a quien la mantiene, porque los textos, los documentos y ya hasta una tradición leen el Tractatus incluyendo esos elementos.

Dicho esto, lo que tenemos que entender y asumir como un compromiso todos aquellos que leemos este texto de Wittgenstein en clave de voluntad schopenhaueriana es que la nuestra tampoco es una interpretación definitiva ni mucho menos.

No somos inocentes de «interpretación», pero tenemos en alta consideración nuestra «conquistada ingenuidad».

\section{Conclusión}

El texto de Anscombe que analizamos críticamente cumple un papel político que encontramos difícil e innecesario negar. Nuestro artículo nunca pretendió colocarse en la posición de acusador. No obstante, en más de un momento hubo necesidad de utilizar una retórica jurídica que seguramente parecía el ejercicio de esa función.

No fue ni es nada fácil encontrar el tono crítico y, a la vez, medido. Téngase en cuenta que lo que acabamos de describir estableció un canon de lectura. Si favoreció que se pueda rechazar cualquier interpretación que utilice a Schopenhauer, aún sin conocer su obra, esto habla más de la recepción del texto que de la intención de la autora.

Describimos los medios discursivos e institucionales con que Anscombe condenó la lectura schopenhaueriana al ostracismo, inclusive antes de que esta lectura fuera posible. Para finalizar, hacemos un análisis de nuestra posición al llevar a cabo esta crítica. Combinemos que Schopenhauer no solo no debe ser obviado como es imprescindible su conocimiento para entender el Tractatus.

11. Roberto Rodríguez Aramayo, en el estudio preliminar a la edición de la Metafísica de las costumbres, de Arthur Schopenhauer, desarrolla la ambigua relación de Freud con la herencia schopenhaueriana (Rodríguez Aramayo, 1993: XXII-XXV). 
De hecho, eso es lo que dice Anscombe. Pero la inclusión de Schopenhauer socava cualquier interpretación que quiera concluir sin dejar mucho en abierto. ¿Qué estamos queriendo señalar con esto? Que la lectura «en abierto» que nosotros defendemos solo es posible en un espacio filosófico atravesado y coordinado por movimientos epocales y/o sociales que conversen entre ellos. Sesenta años atrás tal circunstancia era imposible.

Y si Anscombe no hubiese realizado ese ejercicio de interdicción, ¿estaríamos leyendo el Tractatus? No creemos que hubiese sobrevivido al «verdadero Schopenhauer».

El libro de Elizabeth Anscombe persuade metódicamente. Lo que llamamos "complicaciones» en realidad fue un necesario juego de cartas marcadas. Insistimos en la pertenencia de una interpretación a su época. Sesenta años atrás lo que importaba era el orden, no necesariamente la justicia. Ese orden fue el del Estado y de la democracia liberal. Era el auge de la Guerra Fría, y ninguna filosofía escapa de la sociedad de su tiempo.

El libro de Anscombe es un monumento, un tótem con el que protegió un punto de vista que no era solo de ella. Es más que importante conocer y comprender el carácter político que siempre tendrá la filosofía en su oficio de pensar los límites y más allá de ellos.

\section{Referencias bibliográficas}

Anscombe, G.E.M. (1965). An Introduction to Wittgenstein's Tractatus. Nueva York: Harper \& Row Publishers.

- (1977). Introducción al "Tractatus" de Wittgenstein. Buenos Aires: El Ateneo.

- (1989). "La simplicidad en el "Tractatus"». Traducción de Alberto Vargas e Isabel Cabrera. Dianoia, año xxxv, 35, 1-10.

Barrett, Cyril (1994). Etica y creencia religiosa en Wittgenstein. Traducción de Humberto Marraud González. Madrid: Alianza Editorial.

Barthes, Roland (2006). Mitologías. Traducido por Rita Buongermino, Pedro de Souza y Rejane Janowitzer. Río de Janeiro: Difel.

Carel, Havi y Gamez, David (eds.) (2008). Filosofia contemporânea em ação. São Paulo: Artmed.

López de Santa María Delgado, Pilar (1986). Introducción a Wittgenstein: Sujeto, mente y conducta. Barcelona: Herder.

Marrades Millet, Julián (2011). «Subject, World and Value. (Some Hypotheses on the Influence of Schopenhauer in the early Wittgenstein)». En: Perissinotto, Luigi y SanféLIx, Vicente (eds.). Doubt, Ethics and Religion: Wittgenstein and the Counter-Enlightenment. Frankfurt: Ontos Verlag.

Martínez, Horacio Luján (1998). «William James y su influencia sobre el misticismo wittgensteiniano». Revista de Filosofía. Universidad del Zulia, Venezuela, 87-105.

- (2001). Subjetividade e silêncio no Tractatus de Wittgenstein. Cascavel, Paraná, Brasil: Edunioeste. 
- (2010). "Alcance y pertinencia de las lecturas éticas del Tractatus de Wittgenstein». Ideas y Valores, LIX (142), 111-130. Universidad Nacional de Colombia.

- (2014). «Wittgenstein y la Conferencia sobre ética como texto de transición: Observaciones sobre los cambios en torno al concepto de "voluntad" en su obra». En: Balla, Mariano y Tomasini Bassols, Alejandro (orgs.). Wittgenstein en español IV. Santa Fe: HyA Ediciones, 89-116.

McGuinness, Brian (1966). "The Mysticism of the Tractatus». The Philosophical Review (julio), 305-328.

Rodríguez Aramayo, Roberto (1993). «Estudio preliminar. Excurso freudiano». En: Schopenhauer, Arthur. Metafísica de las costumbres. Madrid: CSIC.

Schopenhauer, Arthur (2005). O mundo como vontade e como representação. Traducción, presentación y notas de Jair Barboza. São Paulo: UNESP.

- (2009). Die Welt als Wille und Vorstellung. Colonia: Anaconda.

Simôes, Eduardo (2012). Hertz, Wittgenstein e a Representação do Mundo. Curitiba, Brasil: CRV.

Stenius, Eric (1964). Wittgenstein's Tractatus: A critical exposition of its main lines of thought. Oxford: Basil Blackwell.

Wittgenstein, Ludwig (1965). «Wittgenstein's Lecture on ethics: Notes on Talks with Wittgenstein (Friedrich Waissmann). Some developments in Wittgenstein's view of ethics (Rush Rhees)». The Philosophical Review, LXXIV (1) (enero).

- (1971). Prototractatus: An early version of Tractatus Logico-Philosophicus. Editado por B.F. McGuinness, T. Nyberg y G.H. von Wright. Traducido por D.F. Pears y B.F. McGuinness. Introducción histórica de G.H. von Wright y un facsímil del manuscrito del autor. Nueva York: Cornell University Press.

- (1988). Investigaciones filosóficas. Barcelona: UNAM / Editorial Crítica.

- (1990). Conferencia sobre ética. (Con dos comentarios sobre la teoría del valor). Traducción de Fina Birulés. Introducción de Manuel Cruz. Barcelona: Paidós.

- (1992a). Gramática filosófica. México: Universidad Nacional Autónoma.

- (1992b). Lecciones y conversaciones sobre estética, psicología y creencia religio$s a$. Traducción e introducción de Isidoro Reguera. Barcelona: Paidós.

- (1993). Tractatus Logico-Philosophicus. Introducción de Bertrand Russell. Traducción, presentación y ensayo introductorio de Luiz Henrique Lopes dos Santos. São Paulo: EDUSP (Editora da Universidade de São Paulo).

- (1997). Ocasiones filosóficas. 1912-1951. Madrid: Cátedra. Teorema.

- (2009). Cuadernos de Notas (1914-1916). Traducción de Juan David Mateu Alonso. Prólogo de Vicente Sanfélix Vidarte. Madrid: Síntesis. 
Horacio Luján Martínez es doctor en Filosofía (2001) con estadía postdoctoral en el Centro para el Estudio de la Democracia, Universidad de Westminster (Londres, Reino Unido), durante el período 2015-2016. Es autor de libros, artículos y capítulos sobre la filosofía de Ludwig Wittgenstein y sobre las relaciones entre lenguaje, ética y política. Actualmente es profesor en el Curso de Filosofía de la Facultad de Humanidades y Artes de la Universidad Nacional de Rosario (UNR). Rosario, Santa Fe, Argentina.

Horacio Luján Martínez was awarded a PhD in Philosophy of Language from the State University of Campinas (Brazil) in 2001. He was visiting researcher at the Centre for the Study of Democracy at the University of Westminster (UK) in 2015-16. He has published works on the philosophy of Ludwig Wittgenstein and the relationships between language, ethics and politics. He currently teaches at the School of Philosophy of the College of Humanities \& Arts of the National University of Rosario (UNR in Argentina). 